\title{
FORMAÇÃO DE BIBLIOTECÁRIOS PARA UMA SOCIEDADE LIVRE
}

\section{UNIVERSITY EDUCATION OF LIBRARIANS FOR A FREE SOCIETY}

\author{
Francisco das Chagas de Souza - Doutor em Educação \\ Departamento de Ciência da Informação - Universidade Federal de Santa Catarina \\ chagas@,ced.ufsc.br \\ souza@amja.org.br \\ http://www.ced.ufsc.br/bibliote/dep/fcscv.htm
}

\section{RESUMO}

Analisa as condições de ensino e formação de bacharéis em biblioteconomia, que hoje predominam no Brasil, e questiona sobre as possibilidades da superação de uma estrutura e práticas de ensino pouco dinâmicas pela utilização de práticas de ensino e aprendizagem que dêem ênfase ao processo que leva o estudante a aprender a aprender.

Palavras-chave: Ensino de Biblioteconomia - Brasil; Formação de Bibliotecários - Brasil.

\section{1 - INTRODUÇÃO}

Ser cidadão vivente em uma sociedade livre, implica poder ter nesta a formação de profissionais comprometidos com a construção permanente dessa sociedade e preparados para atuar no sentido de que essa sociedade fique cada vez mais livre. Para isso, é necessário que, ao menos em campos como a Educação, Biblioteconomia e outros relacionados a profissões de perfil humano e social, uma parcela importante da ação profissional se realize pela pedagogia da crítica. Esta atitude requer que se eduque para a análise e julgamento permanente do agir, no sentido de ver onde é necessário e prover as intermediações adequadas para a transformação de uma realidade que só é parcialmente dada.

Por esta razão, a atuação dos profissionais das áreas sociais, em geral, e da Biblioteconomia, em particular, depende de como esses profissionais foram preparados academicamente; de como se relacionaram e compreenderam os fatos da realidade; de como foram orientados a ver quais os limites que devem ser superados a fim de que o alcance de seu trabalho seja cada vez mais inclusivo, isto é, que seja cada vez mais orientado para as novidades que deve implementar a fim de que as pessoas que compõem as camadas sociais menos protegidas legalmente e desprivilegiadas social e politicamente possam ser integradas e tornadas cidadãs, no sentido clássico que esse conceito adquire a partir da filosofia iluminista.

Nessa perspectiva de discussão, a formação de bibliotecários no Brasil está sempre em cheque, carecendo do permanente olhar crítico de quem a faz ou com ela se relaciona, a fim de superar, melhorar e fazer avançar o modo com que está sendo feita. Como exercer esse olhar crítico, é uma das preocupações recorrentes.

Este texto, tomando por ponto de partida esta preocupação, coloca como seu objetivo perceber e refletir uma trama que possa apontar um rumo para o aprofundamento da discussão. Desse modo, vê o contexto social e econômico como fundamental devendo ser pesquisado pela Biblioteconomia (Social), sendo os resultados dessa pesquisa referência básica para a melhoria de seu ensino no país. Ao partir desse ponto, o texto pretende resgatar o significado da necessidade de se definir um perfil do que seria(m) o(s) bibliotecário(s) necessário(s). 
Se o(s) bibliotecário(s) necessário(s) não está, virtualmente, sendo preparado de modo adequado pela escola de biblioteconomia existente no Brasil, como se deve proceder para chegar a isso? Um dos tópicos tratados no trabalho discute traços do ensino que está sendo realizado e, na seqüência, remete a discussão para um modelo de ensino possível, em termos de conteúdo e prática, isto é, um ensino que deveria ser.

A partir dessa discussão - uma dupla face o ensino que está sendo e o ensino que deveria ser - este trabalho pretende ser uma contribuição no aprofundamento da discussão, necessária, de como avançar na oferta do ensino de graduação (bacharelado) em Biblioteconomia no país.

\section{2 - SOCIEDADE E ECONOMIA NO BRASIL}

Para enxergar, com uma razoável profundidade contextual, a sociedade e economia no Brasil, do ponto de vista da transformação da realidade cultural e, simultaneamente, do ponto de vista das exigências que a sociedade e a economia nacionais fazem à atuação bibliotecária, um dos olhares pode ser sobre os macroacontecimentos dos últimos setenta anos, levando em consideração, dentre outras, variáveis tais como:

a) Crescimento da população urbana e decréscimo da população rural;

b) Evolução quantitativa do PIB;

c) Evolução quantitativa da Produção industrial;

d) Evolução quantitativa do número de estudantes formados em ensino superior e em quais áreas;

e) Evolução quantitativa do número de estudantes existentes no ensino médio.

Neste trabalho, não se fará a exibição destes dados no todo, disponíveis nos sites do IBGE e IPEA, por exemplo. Contudo, ele traz o entendimento de que indicadores desta natureza têm a empiricidade suficiente para, uma vez analisados, inserirem uma visão de qualidade que permite ver o impacto que exercem sobre a existência concreta dos indivíduos e de suas ações no interior da sociedade.

Este impacto, provocado por tais dados, não decorreria pura e simplesmente da evolução dos números, mas esses números têm a capacidade de expressar, sobretudo, quais as políticas sociais e públicas que foram traçadas ao longo dos últimos setenta anos e os impactos que produziram.

Porém, cabe aqui, antes de continuar a discussão, observar que, no caso brasileiro, o delimitador cronológico de setenta anos, iniciando nos anos 1930, responde a um recorte de tempo em que o estado Brasileiro inaugurou um modelo de estrutura econômica e política orientado para o mesmo fenômeno mundial do corporativismo que, nas profissões, significou o fechamento político e jurídico das mesmas em suas categorias; a criação de legislação específica permitindo a proteção de territórios profissionais, levando, em várias situações, as escolas profissionalizantes universitárias a aprisionarem suas ações educacionais e pesquisadoras aos limites de uma castradora reprodução dos fundamentos e teorias elaborados em e para outras sociedades, com dinâmicas culturais diversas e estruturadas sob outros modelos sociais e econômicos.

Feita esta observação, com o fim de situar o olhar metodológico do tema, é preciso ter em mente que se fará neste texto o levantamento de alguns aspectos que permitiriam aprofundar as variáveis já apontadas e sua correlação com a capacitação de um contingente de profissionais que pudesse dar conta para esta sociedade e 
economia das respostas que estas requerem. No entanto, dados quantitativos neste trabalho, com efeito de demonstração, serão apresentados apenas uns poucos, referentes aos anos noventa.

Com relação ao Crescimento da população urbana e decréscimo da população rural, os dados apresentados pelo IBGE para 1996 mostram uma população total de 157.070.160, sendo 123.076.830 urbana [78,35 \%] e 33.993 .337 rural [21,65 \%]. Essa relação percentual é praticamente inversa à existente em 1930, segundo dados da mesma fonte.

Para o estudo da evolução da atividade bibliotecária no Brasil, esta variável traz uma série de questões. Partindo dela, caberia aos pesquisadores em Biblioteconomia social brasileira perguntarem ao menos:

- que usuários, nos diversos momentos dessa trajetória histórica e social, foram e vêm sendo produzidos para os sistemas bibliotecários existentes no país?

- quais metodologias novas, derivadas de uma prática ou adaptadas para o estudo dessa transição de perfil, são necessárias?

- quanto de investimento financeiro, em cada período, seria necessário para adaptar os usuários aos novos ambientes que vinham sendo instaurados?

Acerca da do PIB (Produto Interno Bruto) per capita, os valores convertidos em dólares pelo IBGE, para 1996, indicam que "cada brasileiro" teve uma produção no ano equivalente a US\$ 4.920,36. No entanto, informa a mesma fonte, o Rendimento médio mensal em R \$ teria ficado em 290,00, considerada a população de 10 anos e mais de idade, com ou sem rendimento.

Esta variável poderia ser estudada pelos pesquisadores em Biblioteconomia social brasileira em comparação com outros aspectos como quantidade de bibliotecas de acesso universal, além de questões tais como:

- O PIB brasileiro, ou melhor ainda, esse e o Rendimento mensal do brasileiro foi e é compatível com a produção de excedentes de renda que podem ser canalizados para o consumo de saber e cultura estética, assim como para os seus meios?

- Em que momentos, nos últimos setenta anos, houve parada de crescimento dos rendimentos dos trabalhadores e como isso se refletiu nas atividades bibliotecárias?

- Como cada momento econômico singular refletiu-se nos investimentos sociais e, em particular, nos investimentos em bibliotecas, em edição de livros, no registro de edições na Biblioteca Nacional

Também é importante, nesta variável, enxergar:

- $\quad$ sua compatibilidade com o custo de subsistência do trabalhador;

- a equivalência relativa entre esta renda, o crescimento da população, o perfil do PIB, a trajetória da produção industrial, a capacidade da geração de excedentes para para a aquisição de informação e pagamento do custo de comunicação, correio, telefone, etc. 
No que toca à Produção industrial, uma análise de sua evolução nos últimos setenta anos, permitiria alguma projeção de saber sobre sua tendência, dando uma visão de seu crescimento, estabilização ou retrocesso. A pesquisa em Biblioteconomia social brasileira poderia, ao tratar dados dessa natureza, dimensionar parte importante do mercado profissional bibliotecário e do alcance do currículo em termos de conteúdo e profundidade.

Muito importante nesta variável é verificar, dentre outros:

- $\quad$ quais os principais setores de atividade da indústria;

- quanto de sua produção era canalizada para consumo interno ou para exportação;

- se a matéria-prima utilizada era nacional ou importada (e em que percentual era empregada na elaboração do produto final);

- quais os mercados ou países receptores desses produtos;

- que tipo de informação deveria ser e era agregada aos produtos;

- qual a estimativa de custo do insumo informação sobre o produto;

- quais os tipos de processamento ou elaboração a informação exigia;

- quem poderia realizar esta tarefa;

- que tipo de profissional e de treinamento era exigido e com que grau de habilidade para o tratamento documental dessa informação;

Sobre $O$ número de estudantes formados em ensino superior encontra-se no INEP dados de 1997 que mostram um total geral de 274.384 concluintes em todas as áreas de conhecimento. Uma análise de números de concluintes nos últimos setenta anos daria uma visão das necessidades científicas e profissionais da sociedade e da economia brasileiras, permitindo compreender o alcance da ação bibliotecária e a extensão dos conhecimentos a serem atendidos. Além disso, a pesquisa em Biblioteconomia social no país, poderia agregar outras questões como:

- quais as áreas profissionais que conseguiram implantar cursos universitários nesses anos;

- qual foi a evolução acadêmica dessas áreas;

- onde a educação para estas áreas está geograficamente mais concentrada;

- qual a relação entre estas e o perfil do estado de federação onde está instalada;

- quais as áreas que têm cursos instalados em cidades segundo seu porte populacional;

- como a Biblioteconomia se inseriu no conjunto dessas áreas;

A respeito do Número de estudantes existentes no ensino médio, dados do INEP, referentes a 1998, dão conta do total de 6.968.531, em 17.602 estabelecimentos. Entre 1930 e 2000, esse nível de ensino sofreu várias transformações, ora com ênfase em uma formação mais propedêutica, ora com ênfase em uma formação mais técnica / tecnológica, conforme os interesses econômicos e políticos que mais influenciaram, na oportunidade, as tomadas de decisões sobre o projeto educacional do país. A pesquisa em Biblioteconomia social poderia estar aprofundando questões que permitissem conhecer: 
- como foram constituídas as bibliotecas para atender a esse nível de ensino;

- que papéis os bibliotecários desempenharam nestas bibliotecas;

- $\quad$ em que regiões estas bibliotecas estavam mais concentradas e como evoluíram no período em estudo;

- como a teoria biblioteconômica foi adaptada nestes estabelecimentos;

- que tipo de aplicação aí tiveram as ferramentas de organização do acervo documental;

- se foi produzida alguma teoria biblioteconômica no Brasil para aplicar a este tipo de estabelecimento;

Outras variáveis são pordemais importantes de serem tratadas. Por exemplo, as Taxas de analfabetismo, entre 1930 a 2000. Sua proporção era muito alta no início do período e vem sendo vencida paulatinamente, em que pesem notáveis questionamentos sobre a realidade dos dados apresentados nas estatísticas oficiais. Contudo, para a pesquisa em Biblioteconomia social é importante observar onde se concentram, historicamente, em âmbito regional, o maior número de analfabetos, qual a economia predominante, qual a renda financeira média da população próxima, etc. Também, nessas regiões, é importante saber como atuou a Biblioteconomia, que planos de ação e projetos a categoria profissional ofereceu à sociedade, que tipo de aplicação de trabalho foi feita considerando os referenciais fornecidos pela Declaração dos Direitos Humanos sobre o acesso à informação e o seu uso ou pelos Manifestos internacionais sobre o acesso e uso dos serviços ofertados pelas Bibliotecas Públicas e pelas Bibliotecas Escolares, por exemplo.

\section{3 - PERFIL DO BIBLIOTECÁRIO NECESSÁRIO}

O perfil do bibliotecário necessário ao país, de 1930 a 2000, certamente foi sendo alterado conforme quaisquer variáveis que se tome para análise. Nas variáveis acima destacadas, encontra-se a possibilidade de desvelar-se fortes modificações nesse perfil na medida em que seja comparada a evolução dos números dados pelas fontes estatísticas e a ação profissional na área. Como são variáveis estruturais que alteram-se permanentemente conforme a conjuntura mundial, e mesmo com o fechamento corporativista, no âmbito econômico e político, elas e os fatos que representam colocam também em discussão as inevitáveis mudanças de interesses, necessidades, atitudes e comportamentos dos usuários, especialmente quando vistos:

a) como leitores sob a perspectiva estético-culturalista, e/ou

b) como empregadores instrumentais da informação obtida no sistema bibliotecário.

Assim, para além da diferenciação dos usuários, dada em a) e em b) acima, havia e há, seguramente, um processo de evolução do uso e emprego da leitura, entre outras coisas, como decorrência da modernização e ampliação da indústria editorial e gráfica e sua competição com o rádio, a televisão, o cinema e, hoje, com a Internet.

Desse modo, esses traços que demarcam a atuação profissional e científica da Biblioteconomia praticada e ensinada no Brasil não podem ser dados simplesmente pela expressão da importação de siglas e modismos, a exemplo do que se verifica nas recomendações finais tomadas ao longo da trajetória dos CBBDs, especialmente na composição dos conhecimentos a serem integrados na formação do bibliotecário. É inegável que foi um esforço importante o da categoria bibliotecária brasileira em perceber o desenvolvimento do quadro 
profissional externo, mas que, em paralelo a isso, apenas este esforço não implicou em mudança benéfica ao conteúdo curricular ofertado desde os anos 30 no país. Aliás, este currículo, em sua essência, dada por ideologia e conteúdo, continua concentrado ainda hoje na perspectiva instrumental (documento, informação, tecnologia) com com pouca ênfase na perspectiva humana (desejos, necessidades e gozo da informação por um lado e, por outro, atitudes de uso, crescimento humano e benefícios materiais trazidos pelo uso da informação obtida nos sistemas bibliotecários).

Assim, a perspectiva instrumental tem sido dominante na medida em que é importada ou imposta e para ela se dispensam os maiores investimentos em sua importação e uso, inclusive o investimento didáticopedagógico. Ela exige pouco mais que memória e é imposta por ter como matriz ideológica o aculturamento que o pragmatismo americano vem forjando sobre o mundo, mas em particular, sobre o Brasil neste século, conforme se deduz de autores como Júlia Falivene Alves, Paulo Freire e Heinz Dieterich Steffan.

A perspectiva humana da biblioteconomia, traduzida aqui pela expressão Biblioteconomia social, exige pesquisa nacional, com investimento em capacitação de pesquisadores capazes de entender, explicar, e ensinar uma Biblioteconomia para a autonomia nacional. Uma biblioteconomia que possa produzir uma teoria biblioteconômico-humana para o Brasil, inclusive incorporando o melhor do conhecimento instrumental internacional, submetendo-o ao nosso modelo de apropriação e não o inverso como hoje ocorre na América Latina (Sabor).

Assim, o bibliotecário necessário nem é o que se deliberou no afogadilho das sessões finais de recomendações dos CBBDs, especialmente a partir do segundo, em 1959, sem revisões ao longo do tempo, nem é o que resulta das pesquisas enviesadas e direcionadas pelo equivoco que se traduz, no Brasil, pela sigla MPI [MIP].

Desse modo, ao longo de todo esse tempo, quase um século, não se tem nas tomadas de decisões desta categoria profissional a construção do bibliotecário necessário e nem possível, mas de um amálgama de discursos e sentimentos pessoais que, sem maiores discussões e aprofundamento, incorpora o sentido de um profissional que se porta com a atitude do que Paulo Freire caracteriza como o ser oprimido. Embora não seja por má intenção ou por culpa da categoria profissional, o que se tem é um bibliotecário com uma imagem sempre falsa de si próprio como um bibliotecário atualizado (mesmo quando instrumentalmente o é) e capaz de pensar e produzir transformações na sociedade. E é mais falso ainda na concretude de sua existência, porque não pensa sobre o seu fazer e nem lê, como destaca Josefa Sabor para os bibliotecários da América do Sul no geral e da Argentina em particular, ao citar uma frase de Octave Uzanne que a atribuía a Charles Nodier: "Não conheço gente mais honesta que os bibliotecários: jamais tocam o tesouro que se lhe há confiado".

Este quadro, transposto como uma análise sócio-profissional para o contexto brasileiro, possibilita pintar o bibliotecário deste país como uma caricatura de bibliotecário, como já o fez há anos Edson Nery da Fonseca, ao caracterizar os bibliotecários como eqüestres e pedestres, colocando a maioria desses nesta última categoria. Mas o bibliotecário brasileiro está assim pintado também em termos de América do Sul, [pois não é visível em sua presença pois não tem contribuição internacional reconhecida como relevante]. Isso é perceptível em uma das perguntas que Romá Seguí e Lola Miñarro fazem a Josefa Sabor, por ocasião de entrevista realizada para o periódico espanhol Métodos de Informação, publicado em setembro de 1999. A pergunta foi formulada da seguinte maneira: "Desta parte do oceano, a produção bibliográfica da América do Sul que, sobre a 
Biblioteconomia, se tem percebido, pode-se resumir em três pessoas: Domingo Buonocore, Carlos Victor Penna e Josefa Emília Sabor... "

Nos termos em que está colocada a pergunta, todo o conjunto de profissionais bibliotecários da América do Sul é visível na Espanha pelas figuras dos argentinos Buonocore, Penna e Sabor. Ora, isto é preocupante para a Biblioteconomia brasileira, na medida em que também neste campo profissional e científico o mundo não conhece o Brasil, a despeito de estarem aqui mais de 30 cursos de Graduação, Mestrados e Doutorados.

A preocupação deve ser maior, na medida em que dá para inferir que nossa academia é constituída por não mais que meros "Cursos" bibliotecários, reprodutores, servidores e não criadores e senhores.

É evidente que isto demarca algo bem mais grave: nem a categoria profissional, nem os professores, nem os "pesquisadores", nem os dirigentes políticos da categoria bibliotecária chegaram ainda, por suas deliberações e atuação, ao mundo que situa os leitores na perspectiva humana. Disso se deduz que, ao longo dos anos, a categoria bibliotecária brasileira não adquiriu a capacidade de querer por si. Por esta razão autoriza a escola a ser reprodutora e castradora, por isso permite que se faça pesquisa que não inova métodos ou processos e, portanto, não gera conhecimento que sirva à nação brasileira e, por fim, gera dirigentes políticos bibliotecários bisonhos, incapazes de perceber fatos relevantes e desenvolver ações que possam alcançar a sua mais profunda consciência e a do grupo bibliotecário no sentido de produzir a transformação de que todos falam.

O álibi apresentado para a ocorrência da atitude submissa por parte dos bibliotecários é que a mesma ocorreria também em outras categorias profissionais atuantes no Brasil. No entanto, os CBBDs e os cursos de Biblioteconomia, e os pesquisadores em biblioteconomia e os dirigentes políticos das Associações profissionais pouco fazem para que se modifique isto, além do recorrente discurso da transformação.

Pelo visto, até agora, parece que o teor deste texto, pela sua forma de análise, coloca a escola de biblioteconomia brasileira como refém de uma acrítica história interna da categoria profissional. Por que isso ocorre? Não seria porque os professores especialistas desses cursos foram psicológica e profissionalmente forjados com referenciais acríticos, com restrições ao pensar, com a idéia de mundo paralítico, dependente? Parece que sim! Dessa maneira, como fica a afirmação recorrente de que é necessário mudar o ensino na área? Como mudar um ensino que está sendo para um ensino que deveria ser?

\section{4 - O ENSINO QUE ESTÁ SENDO}

O ensino (de Biblioteconomia) que está sendo, segundo dados do INEP (Censo do Ensino Superior), formou em 1997 o número de 765 bacharéis, representando 0,27\% do total de alunos do ensino superior brasileiro (274.384) concluintes naquele ano. Em 30/04/98, segundo a mesma fonte, havia 5.235 estudantes de Biblioteconomia matriculados nos 32 cursos de graduação existentes no país $(0,46 \%$ do total dos cursos existentes). Esse contingente estudantil representava $0,24 \%$ do total de alunos do ensino superior brasileiro (2.125.958) matriculados naquele ano.

Esses dados quantitativos mostram uma questão inicial que reflete razões como: 
- a existência de pequeno número de alunos por curso o que poderia ser decorrente de características especiais do ensino na área, como ensino em laboratórios, ensino assistido em campo de estágio, etc.;

- o elitismo do ensino na área, decorrente pura e simplesmente da baixa relação professor / aluno;

- a pouca demanda social pelos cursos da área, com entrada e permanência de pequeno número de estudantes;

- todos os itens anteriores reunidos.

Se colocada a terceira razão como hipótese a ser investigada pelas escolas, sua confirmação poria em questão a noção do compromisso social que a área, como um todo, e o ensino de biblioteconomia teriam para com a sociedade, na medida em que a participação percentual do número de escolas de biblioteconomia no universo de cursos superiores brasileiros em comparação com o número de alunos e de concluintes é quase o dobro. Isso coloca em discussão o custo financeiro de formação do aluno de biblioteconomia, por um lado ou, por outro, a baixa qualidade da infra-estrutura de tantos cursos.

Proposto como hipótese, esse assunto deve merecer pesquisa especialmente no campo econômico da formação bibliotecária, que poderia concluir: 1) ou que é possível receber mais estudantes nos atuais cursos; ou 2) que não são necessários alguns dos cursos de graduação (bacharelado) em Biblioteconomia existentes no país.

Além desse aspecto, o ensino que está sendo se relaciona ou responde a que demanda social e econômica?

Não se tem conhecimento, ao menos público, de parte das escolas de Biblioteconomia brasileiras, sobre:

- A quem atende seu projeto de formação de pessoal?

- Qual o perfil real da sociedade para a qual a escola direciona seus formandos?

- Qual a possibilidade de expansão dessa demanda contratadora de serviços profissionais bibliotecários?

- Que conteúdos e habilidades profissionais devem ser ministrados e desenvolvidas e como estão situados no projeto do Curso e refletidos em seu currículo?

- Qual o custo da ministração desse conteúdo em termos de pessoal, instalações, equipamentos, laboratórios locais e extralocais, viagens de estudo, etc?

A falta dessa visão no ensino que está sendo, pode ter como causa o mais absoluto empirismo na gestão dos cursos de Biblioteconomia, o que termina por não sustentar o discurso desses cursos na busca por maiores investimentos financeiros públicos para melhorar a qualidade, implantar novos currículos, fomentar a divulgação de produção acadêmica, criar produtos nacionais para tratamento e gerenciamento da informação documentária, etc.

Essa combinação de fatos, pode ser mais do que explicadora do modo como a escola de biblioteconomia brasileira tem permanecido alienada em seu conteúdo curricular que, de 1962 a 1982, congelou uma certa estrutura; de 1982 até agora (2000) congelou outra estrutura não muito diferente da primeira e trabalhou um conteúdo nem sempre atual e preparado para responder ao contexto social e econômico. Ademais, como se vê, a partir da discussão dos Parâmetros Curriculares Nacionais da Área, ainda em análise no CNE (Conselho Nacional de Educação), não há avanços no sentido de libertar os cursos do vício ideológico do currículo mínimo nacional. 
Essa limitação do ensino que está sendo parece tão forte porque sua estrutura, como até agora analisada, não responde a um quadro estudado, aprofundado, assimilado pela área a partir de pesquisa permanente do contexto social e econômico nacional que uma frente de investigação como a Biblioteconomia social poderia fornecer

Isso exibe, à exaustão, porque o ensino de Biblioteconomia que está sendo, representa muito claramente a perspectiva do usuário como "empregador instrumental da informação obtida no sistema bibliotecário". Neste quadro circunstancial, é comum a falsa dicotomia da "formação geral cultural" / "formação técnica profissional" que existe no discurso bibliotecário. Por essa visão dicotômica, é como se os conteúdos técnicos não fossem criação humana e, portanto, é como se seu ensino não pudesse resgatar, permanentemente, o seu sentido humanista (filosofia, antropologia, sociologia, psicologia, história e prática da criação e da ação bibliotecária, entre outros enfoques). Por esta falsa dicotomia, que se estende por toda a vida profissional da maioria dos bibliotecários formados no Brasil, os cursos são, de fato, meros espaços de instrução e aprendizagem da aplicação de regras e macetes técnicos como se o saber bibliotecário fosse destituído de todo o sentido humano e como se o conhecimento técnico fosse uma concepção advinda de outros planetas.

Essa insuficiência epistemológica no tratamento educacional do conteúdo técnico da Biblioteconomia faz com que este ensino neutralize a capacidade de pensar e de expandir-se do aluno de Biblioteconomia, com péssimos reflexos futuros no exercício da profissão. De outro lado, mostra que os quadros docentes estão majoritariamente constituídos de professores conteudistas quando em essência seriam necessários mais docentes metodologistas. Quero dizer com isso, que muitos professores estão preocupados não em como ensinar a forma de inserir o conhecimento técnico como resposta a uma necessidade identificada na sociedade, mas sim de ensinar o conteúdo técnico como uma lei universal, que se aplica independentemente de qualquer sociedade, desprezando o fato de que é na forma de descobrir primeiro o que a sociedade precisa que se vai poder oferecer a alternativa que satisfaz seu desejo, necessidade e interesse ao custo que pode pagar. Assim, a incapacidade de historicizar e analisar as realidades sociais, culturais e econômicas tende a ser considerada uma característica natural do conhecimento técnico em biblioteconomia quando, de fato, trata-se de uma deficiência educacional.

Em face disso, a questão fundamental é que rumo dar ao ensino e à pesquisa para se chegar a uma prática pedagógica em biblioteconomia no Brasil que caminhe no rumo do ensino que deveria ser.

\section{5 - O ENSINO QUE DEVERIA SER}

Costuma-se acreditar que tudo o que deveria ser já está contido no que ainda é. Esse é um dos fundamentos da investigação científica que não se satisfaz com as verdades já alcançadas. Dos resultados existentes tende-se sempre a caminhar, com novas indagações, para outros dever ser.

No caso do ensino de Biblioteconomia no Brasil, o embrião do ensino que deveria ser já está presente em algumas escolas, sob várias formas, e dentre elas estão os de programas de iniciação científica, meio pelo do que se ensina os estudantes a aprender a aprender.

Uma estimativa a partir de dados sobre o apoio à iniciação científica no país (PIBIC/CNPq, PET/CAPES, Programas das Fundações de Apoio às Atividades Científicas nos Estados e recursos das próprias universidades) permite aproximar um cálculo variável de 1,0 a 1,5\% na participação de estudantes, por área, nesses fundos. 
Considerando isso na Biblioteconomia, o ensino que deveria ser agregaria também a aproximação de estudantes de graduação com o trabalho de pós-graduandos em Biblioteconomia e Ciência da Informação de algumas das escolas brasileiras e chega-se a uns 2,0 \% de um ensino de Biblioteconomia que deveria ser.

A questão fundamental da discussão está em como dar o ensino que deveria ser para os demais $98,0 \%$ de estudantes de graduação, incluídos os de Biblioteconomia, que estudam no Brasil. As limitações passam por falta de recursos financeiros para a formação de boas Bibliotecas nas escolas, produção de literatura nacional, pesquisa de temas e metodologias de aprendizagem que contribuam com a educação bibliotecária no país, constituição de rede de periódicos científicos e de divulgação em biblioteconomia de larga difusão, acesso aos congressos, simpósios e outros eventos bibliotecários aos estudantes, com custo zero ou fortemente subsidiados. Parte dessas limitações tem como razão, na sua origem, a questão da classe social da maioria dos estudantes.

Os estudantes de Biblioteconomia, em sua maioria, precisam não apenas de subsídios financeiros para estudar, mas também de meios para sobreviver, e, por isso, cito como exemplo a UFSC, onde o que acontece não é muito diferente do que se verifica na maioria das IES brasileiras. Nela, muitos desses estudantes exercem subempregos e bolsas trabalho. Assim, são estudantes que precisam, mais que muitos de outros cursos, de ambiente que thes permita formar uma consciência para o estudo, como o ambiente da biblioteca onde possam estudar; como ambientes na universidade onde possam reunir-se, trocar idéias científicas e práticas com os professores e colegas; como viagens de estudo e conhecimento das estruturas e formas de operação dos sistemas bibliotecários; como os seminários de pesquisa em que podem participar como autores; como as revistas estudantis onde podem publicar sua produção reflexiva, e muito mais.

Além disso, esse ensino que deveria ser exige a reciclagem do domínio didático-pedagógico de grande parte dos professores de modo a avançarem da prática conteudista para a prática metodologista. Isso exige não o desprezo pelos conteúdos, ao contrário, exige que a prática do ensinar / estudar seja um caminho em que o importante é auxiliar em como explorar o conteúdo. Por esta prática de ensino e aprendizagem, a avaliação da aprendizagem não se dará encima do que foi retido como conhecimento congelado, mas no modo como o estudante sintetiza um conhecimento e o integra em um contexto real. Dessa maneira, um componente importante desse ensino que deveria ser são os laboratórios como locus operativo e os estudos de casos, a identificação dos casos concretos para estudos resolutivos, a integração comunitária como agente de captação de recursos junto a entidades e empresas como modus metodológico.

Nessa concepção, o ensino que deveria ser coloca professores e alunos como inseridos na sociedade e na economia, dasalienando sua relação com as outras pessoas, com as outras categorias profissionais, tornando pluridisciplinar sua intervenção. Com essa forma de atuação, o professor não deixa de saber o seu saber conteudístico, porém esse seu saber estará em constante aplicação e reelaboração, o que exigirá a abolição das fichas que se repetem, das aulas de há muito preparadas, que seriam substituídas com a prática constante do saber como se adquire saber.

Assim, a indagação mais forte é: como poderíamos iniciar no ensino de Biblioteconomia uma construção curricular e prática de ensino que levasse ao ensino que deveria ser, quando este, substantivamente, depende de uma participação efetiva e concreta de toda a categoria profissional bibliotecária como sócia da transformação valorativa da atuação profissional.

Esta é uma questão que está colocada, na medida em que se repetem, com freqüência, as críticas à escola de Biblioteconomia no Brasil. Porém, para além das críticas não têm surgido propostas e quando surge 
algo intitulado como proposta tende a ser cópia de projetos que lastreiam a formação bibliotecária em outros contextos sociais, culturais e econômicos.

\section{6 - CONCLUSÕES}

Da discussão realizada, fica clara a difícil trajetória a ser percorrida para chegar ao modelo de ensino (de graduação em biblioteconomia no Brasil) que deveria ser. Quais as dificuldades percebidas? A primeira delas tem a ver com o fato de que há insuficiente estudo, feito por pesquisadores em Biblioteconomia, numa frente de investigação que pode ser chamada de Biblioteconomia Social, comprometida com o conhecimento do que compõe e das mudanças existentes nos fatos que estão integrados ao contexto social e econômico do país e de suas regiões.

Esta insuficiência de estudo traduz-se em pouca densidade de sustentação de um conteúdo teóricosocial assimilado pela área. A presença dessa pouca densidade não permite a formação de pessoal capaz de transformar, objetivamente, a precária relação entre prestação e consumo de serviços bibliotecários, pois do lado da oferta desses os referenciais teóricos que orientam as práticas são oriundos de outras sociedades ou são meras improvisações a-científicas e do lado do consumo tem havido, pela mesma causa, uma dificuldade significativa do rompimento dos preconceitos trazidos pelos usuários.

A segunda dificuldade percebida, inteiramente ligada à primeira acima exposta, é que o bibliotecário necessário a uma sociedade como a brasileira, com larga parcela populacional a ser tornada cidadã com consciência dos seus amplos direitos, ainda não está plenamente presente no contexto do país. Isso é real pois, se por um lado não há estudos suficientes e a prática profissional segue teorias importadas, por outro lado, os usuários são tratados como meros utilizadores instrumentais da informação obtida do sistema bibliotecário e, mais grave, como entidades a-temporais e a-históricas. A conseqüência imediata, fazendo-se uma extrapolação dessa atitude, é que por atender a uma sociedade a-histórica o conhecimento profissional necessário ao bibliotecário tende a congelar-se e a desumanizar-se determinando um ensino bibliotecário que separa conhecimento amplo, humanístico, geral - ministrado por professores de outras áreas acadêmicas - e conhecimento específico, técnico, profissional - ministrado por professores "de biblioteconomia". Vem daí, também, o fato expresso pela ministração de "disciplinas técnicas" pelos seus conteúdos instrumentais, como se fora um conhecimento natural, mecânico e não como um conhecimento social e, por isso, humanístico.

Essa circunstância, incrementada por outras variáveis, configura um ensino limitado. Há poucas escolas no país; há poucos alunos mas com uma desproporcional distribuição na relação cursos / vagas quando comparados seus números com os de outras áreas de formação universitária no país.

A aparentemente baixa relação quantitativa cursos / vagas pode estar vinculada com o próprio ensino ministrado, pouco utilizador de uma didática dinamizadora na medida em que está fortemente centrado numa prática de ensino conteudista, ainda que a Biblioteconomia seja, dentre as áreas de conhecimento, uma daquelas na qual se aplica bem uma prática de ensino metodologista, isto é, orientada para um ensino que enfatiza o uso de técnica para o aprender a aprender em vez de técnicas que levam à memorização do conhecimento já sabido.

Essa constatação precisa ser colocada como um mote capaz de induzir a categoria profissional bibliotecária brasileira a aliar-se com a escola de biblioteconomia no sentido da realização de uma outra maneira, 
ou de outras maneiras, que sejam predominantes na formação do bibliotecário para atender ao país. E aí vem a grande dificuldade que centra-se em dois aspectos:

a - carência de largo investimento financeiro na renovação dos recursos materiais (ambiente de estudo, hardware, etc.) e no auxílio aos estudantes (bolsas de iniciação científica ou de aprendizagem de prática acadêmico-profissional no campo, por exemplo) para que se dediquem, fortemente, no estudo de uma biblioteconomia capaz de produzir transformação social;

$\mathrm{b}$ - carência de projeto acadêmico que induza, fortemente, os professores de biblioteconomia a reciclarem sua visão de realidade social e seus métodos de trabalho, levando-os para práticas de ensino que insiram densamente a perspectiva do ensino-aprendizagem pela pesquisa e pela intervenção na realidade concreta da sociedade para que possa ser continuamente transformada.

A partir desta percepção, a conclusão final a que se pode chegar neste trabalho, por ser a menos dolorosa, é a de simplesmente desconhecer o problema tratado, como há anos os bibliotecários brasileiros fazem, desde quando, no VI CBBD, realizado em Belo Horizonte, em 1971, dentre as recomendação finais aprovadas a de número 25 determinou: "Que seja excluida dos futuros congressos brasileiros de Biblioteconomia e Documentação a discussão de assuntos referentes ao ensino e à formação profissional, os quais deverão ser examinados pela ABEBD em suas reuniões e encontros, e posteriormente relatados aos plenários dos congressos profissionais".

Contudo, a conjuntura social, econômica e política atual exige, mais que em qualquer período anterior, uma decisão da categoria bibliotecária brasileira sobre a sua permanência no cenário que se abre para os próximos anos.

\section{ABSTRACT}

It analyzes the conditions of education level of the librarians in Brazil, and questions the possibilities of different forms of education that give emphasis to the process of "learning to learn."

Keywords: Education of Library Science; Education of Librarians; Brazil.

\section{BIBLIOGRAFIA}

ALVES, Júlia Falivene. A invasão cultural norte-americana. 13. ed. São Paulo: Moderna, 1991.

CASTELLS, Manuel. A era da informação: economia, sociedade e cultura. São Paulo: Paz e Terra, 1999. 3 v.

CONGRESSO BRASILEIRO DE BIBLIOTECONOMIA E DOCUMENTAÇÃO (10., Curitiba, jul. 1979). Anais ... Curitiba: Associação Bibliotecária do Paraná, 1980. v. 3 - p. 1167-1174 - Recomendações.

CONGRESSO BRASILEIRO DE BIBLIOTECONOMIA E DOCUMENTAÇÃO (11., João Pessoa, jan. 1982). Anais ... João Pessoa: Associação Profissional de Bibliotecários da Paraíba, 1982. v. 2 - p. 297-303 - Relatório Final (Carta da Paraíba). 
CONSELHO NACIONAL DE DESENVOLVIMENTO CIENTÍFICO E TECNOLÓGICO - CNPq. Programa Institucional de Bolsas de Iniciação Científica- PIBIC. Encontrado em http://www.cnpq.br/pibic/index.htm

CONSELHO NACIONAL DE EDUCAÇÃO - CNE. Encontrado em http://www.mec.gov.br/cne/default.shtm

FEITOSA, Luiz Tadeu. O poço da draga, a favela e a biblioteca. São Paulo: Annablume, 1998.

FERREIRA, Carminda N. C. e outros. 1954-1979 - jubileu dos Congressos de Biblioteconomia e Documentação. Curitiba, 1979.

FONSECA, Edson Nery da. Introdução à biblioteconomia. São Paulo: Pioneira, 1992.

FREIRE, Paulo. Pedagogia do oprimido. 12. ed. Rio de Janeiro: Paz e Terra, 1983.

INSTITUTO BRASILEIRO DE GEOGRAFIA E ESTATÍSTICA - IBGE. SIDRA - Sistema IBGE de Recuperação Automática. Encontrado em http://www.ibge.gov.br

INSTITUTO NACIONAL DE ESTUDOS E PESQUISAS EDUCACIONAIS - INEP. Censo do Ensino Superior - 1998. Encontrado em http://www.inep.gov.br

ONU. Declaração Universal dos Direitos Humanos. $\quad$ Encontrada em http://www.proex.ufu.br/dirhum/univers/decport.html

PERRENOUD, Phillipe. Dez novas competências para ensinar. Porto Alegre: Artes Médicas Sul, 2000.

SABOR, Josefa Emília. Repensar lo pensado o replantear la realidad. [Entrevista concedida]. Métodos de información, sept. 1999. Encontrado em http://www.uv.es/cde/mei/mei32/pag18.html

SOUZA, Francisco das Chagas de. O ensino de biblioteconomia no Brasil no discurso do bibliotecário participantes nos CBBDs entre 1954 e 1982: apontamentos disciplinares para a construçaão do currículo do curso de biblioteconomia. In: CONGRESSO BRASILEIRO DE BIBLIOTECONOMIA E DOCUMENTAÇÃO, 19., jul. 2000, Porto Alegre. Anais ... Curitiba: Associação Rio-grandense de Bibliotecários, 2000. Meio

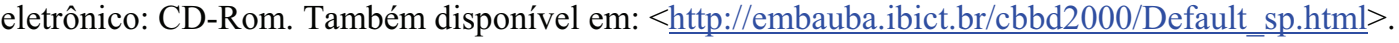

SOUZA, Francisco das C. de. Biblioteconomia, educação e sociedade. Florianópolis: Ed. UFSC, 1993.

SOUZA, Francisco das C. de. Biblioteconomia no Brasil: profissão e educação. Florianópolis: Associação Catarinense de Bibliotecários, 1997.

SOUZA, Francisco das C. de. O Ensino de Biblioteconomia no contexto brasileiro. Florianópolis: Ed. UFSC, 1990.

SOUZA, Francisco das C. de. Modernização e biblioteconomia nova no Brasil. Piracicaba: UNIMEP, 1994. Tese (Doutorado em Educação).

SOUZA, Francisco das C. de Organização do conhecimento na sociedade. Florianópolis: UFSC-CED-Núcleo de Publicações, 1998.

STEFFAN, Heinz Dieterich. Globalização, educação e democracia na América Latina. In: CHOMSKY, Noam; STEFFAN, Heinz D. A sociedade global; educação, mercado e democracia. Blumenau: Editora da FURB, 1999. p. $67-263$.

UNESCO. Manifesto da Unesco sobre bibliotecas públicas - 1994. Encontrado em http://www.ifla.org/VII/s8/ unesco/port.htm

UNESCO. Manifiesto de la biblioteca escolar. Encontrado em http://www.ifla.org/VII/s11/pubs/mani-s.htm 